\title{
CERTAINTY FACTOR UNTUK KLASIFIKASI KELAINAN JANTUNG BERDASARKAN REKAM MEDIS ELEKTROKARDIOGRAM
}

\author{
Sumiati $^{1}$, Akip Suhendar ${ }^{2}$, Fahriyanti $^{3}$ \\ ${ }^{1,2,3}$ Program Studi Informatika Fakultas Teknologi Informasi Universitas Serang Raya \\ Jln. Raya Cilegon Serang - Drangong Kota Serang \\ ${ }^{1}$ Sumiati82@yahoo.com \\ ${ }^{2}$ Akip.suhendar@gmail.com
}

\begin{abstract}
Abstrak -Keterbatasan seorang pakar khususnya pakar penyakit jantung di Provinsi Banten, sedangkan penyakit jantung merupakan urutan tertinggi penyebab kematian, sehingga untuk mendapatkan perawatan kesehatan sangat minim sekali, karena keterbatasan seorang pakar. Untuk mengatasi permasalahan tersebut membuat sistem pakar untuk klasifikasi kelainan jantung dengan pendekatan metode Certainty Factor. Sistem Pakar merupakan suatu cabang ilmu artificial intellegent yang mengadopsi kepakaran seseorang ke dalam suatu aplikasi. Sistem Pakar ini untuk klasifikasi kelainan jantung menggunakan teknik faktor kepastian dengan beberapa aturan premis. Hasil pencarian untuk gejala yang dipilih pasien menunjukkan nilai kepastian dan menunjukkan prosentasi kenyakinan kelainan jantung normal sebesar 89,07 \% sedangkan nilai kepastian untuk jantung abnormal sebesai $89,43 \%$.
\end{abstract}

Kata Kunci - Sistem Pakar,Certainty Factor, Kelainan Jantung, artificial intellegent.

\section{PENDAHULUAN}

Keterbatasan seorang pakar khususnya pakar penyakit jantung di Provinsi Banten, sedangkan penyakit jantung merupakan urutan tertinggi penyebab kematian, sehingga untuk mendapatkan perawatan kesehatan sangat minim sekali, karena keterbatasan seorang pakar. Untuk mengatasi permasalahan tersebut membuat sistem pakar untuk klasifikasi kelainan jantung dengan pendekatan metode Certainty Factor. Sistem Pakar merupakan suatu cabang ilmu artificial intellegent yang mengadopsi kepakaran seseorang ke dalam suatu aplikasi. Sistem Pakar ini untuk klasifikasi kelainan jantung menggunakan teknik faktor kepastian dengan beberapa aturan premis.

Oleh karena itu diperlukan suatu alat atau sistem yang lebih praktis dan memiliki kemampuan layaknya seorang dokter dalam mendiagnosa penyakit. Sistem tersebut adalah sistem pakar yang berusaha mengadopsi pengetahuan manusia ke dalam komputer agar dapat menyelesaikan masalah seperti yang biasa dilakukan oleh pakar atau dokter. Dengan adanya sisem pakar ini, orang awam mampu mendeteksi adanya penyakit pada dirinya berdasarkan.

Hasil analisis penelitian sebuah aplikasi Sistem Pakar Untuk Klasifikasi Kelainan Jantung dengan pendekatan metode Certainty Factor. Sistem Pakar ini untuk klasifikasi kelainan jantung menggunakan teknik faktor kepastian dengan beberapa aturan premis. Hasil pencarian untuk gejala yang dipilih pasien menunjukkan nilai kepastian dan menunjukkan prosentasi kenyakinan kelainan jantung normal sebesar 89,07 \% sedangkan nilai kepastian ssuntuk jantung abnormal sebesai $89,43 \%$.

\section{METODOLOGI PENELITIAN}

Penelitian ini terbagi menjadi beberapa tahap penelitian, dimulai dengan tahap pengumpulan data dan informasi gejala setiap penyakit. Setelah gejala diperoleh informasi, kemudian diklasifikasikan menurut jenisnya penyakit. Jika ada beberapa gejala yang sama untuk penyakit yang berbeda, gejala yang sama disatukan dan kemudian membuat kode gejala untuk dimasukkan ke dalam basis pengetahuan dan dikaitkan dengan jenis penyakitnya. Tahap selanjutnya adalah pengembangan basis pengetahuan menggunakan mesin database MYSQL dan pembuatan aplikasi sistem pakar menggunakan bahasa pemrograman PHP. Tahap selanjutnya adalah pengembangan basis pengetahuan menggunakan mesin database MYSQL dan pembuatan sistem pakaraplikasi, dan kemudian diuji terhadap beberapa pengguna untuk menguji keakuratan hasil akhir. 
Aplikasi yang dibangun sangat user friendly, dimana user dihadapkan dengan beberapa pertanyaan berdasarkan gejala gejala yang dirasakan oleh pasien. Dalam aplikasi ini dibutuhkan jawaban dari user Ya atau Tidak seperti halnya berhadapan dengan dokter pada saat konsultasi. Setelah pasien telah menjawab beberapa pertanyaan yang telah dipilih beberapa gejala, kemudian pasien dihadapkan pada halaman konsultasi untuk memberikan nilai $\mathrm{CF}$ sesuai kenyakinan pasien. Nilai CF ini akan dihitung sesuai dengan nilai CF yang ada di knowledge base.

Pemilihan gejala dapat dilakukan berulang kali selama pengguna yakin bahwa banyak gejala yang dirasakan. Jika pengguna sudah merasa cukup percaya diri, maka pengguna cukup melakukan pencarian hasil akhir. Sistem akan melakukan proses dari kesimpulan gejala CF dipilih dengan nilai yang dimasukkan. Misalnya, konsultasi pengguna sebagai berikut:

\section{Rule 01 (Jantung Normal)}

Rule 1.1 :

IF G05 THEN K02

CFuser $=0,4$

CFrule $=0,6$

Rule 1.2 :

IF G14 THEN K02

CFuser $=0,6$

CFrule $=0,2$

Rule 1.3 :

IF G01 THEN K02

CFuser $=0,6$

CFrule $=0,6$

Rule 1.4 :s

IF G11 THEN K02

CFuser $=-0,4$

CFrule $=-0,6$

Rule 1.5 :

IF G17 THEN K02

CFuser $=0,4$

CFrule $=0,4$

Rule 1.6 :

IF G21 THEN K02

CFuser $=1$

CFrule $=0,6$
Proses perhitungan manual untuk rule 1.1 :

CF Gejala $05=\mathrm{CF}($ User $) * \mathrm{CF}($ Pakar $)$

$$
=0,4 * 0,6
$$$$
=0,24
$$

Proses perhitungan manual untuk rule 1.2 :

$\mathrm{CF}$ Gejala $14=\mathrm{CF}($ User $) * \mathrm{CF}($ Pakar $)$

$$
=0,6 * 0,2
$$$$
=0,12
$$

Proses perhitungan manual untuk rule 1.3 :

$$
\begin{aligned}
\text { CF Gejala 01 } & =\mathrm{CF}(\text { User }) * \mathrm{CF}(\text { Pakar }) \\
& =0,6 * 0,6 \\
& =0,36
\end{aligned}
$$

Proses perhitungan manual untuk rule 1.4 :

$$
\begin{aligned}
\text { CF Gejala } 11 & =\mathrm{CF}(\text { User }) * \mathrm{CF}(\text { Pakar }) \\
& =-0,4 *-0,6 \\
& =0,24
\end{aligned}
$$

Proses perhitungan manual untuk rule 2.5 :

$$
\begin{aligned}
\text { CF Gejala } 17 & =\mathrm{CF}(\text { User }) * \mathrm{CF}(\text { Pakar }) \\
& =0,4 * 0,4 \\
& =0,16
\end{aligned}
$$

Proses perhitungan manual untuk rule 2.6 :

$$
\begin{aligned}
\text { CF Gejala } 21 & =\mathrm{CF}(\text { User }) * \mathrm{CF}(\text { Pakar }) \\
& =1 * 0,6 \\
& =0,6
\end{aligned}
$$

$\mathrm{CF}_{\text {old } 1}=0,3312$

CF combine 2(CFold1, CFgejala01)

$$
\begin{aligned}
& =\text { CFold } 1+\text { CFgejala0 } 1 *(1-\text { CFold } 1) \\
& =0,3312+0,36 *(1-0,3312) \\
& =0,3312+0,240768
\end{aligned}
$$

$\mathrm{CF}$ old $2=0,571968$

$$
\begin{aligned}
& \mathrm{CF}_{\text {combine }} 3(\mathrm{CF} \text { old2 }, \mathrm{CF} \text { gejala11 }) \\
&=\mathrm{CF} \text { old2 }+ \text { CFgejala11 } *(1-\mathrm{CF} \text { old2 }) \\
&=0,571968+0,24 *(1-0,571968) \\
&=0,571968+0,10272768
\end{aligned}
$$

$\mathrm{CF}_{\text {old } 3}=0,6746956$

$$
\begin{aligned}
& \begin{aligned}
\text { CFcombine } 5(\mathrm{CF} \text { old } 4, \text { CFgejala21 }) \\
=\text { CFold } 4+\text { CFgejala } 21 *(1-\text { CFold } 4) \\
=0,726744+0,6 *(1-0,726744) \\
=0,726744+0,1639536
\end{aligned} \\
& \begin{aligned}
\text { CFold5 }=0,89067 & =0,890697 \\
\text { CF Persentase } & =\text { CF old } 5 \times 100 \\
& =0,8907 \times 100 \\
& =89,07 \%
\end{aligned}
\end{aligned}
$$




\section{Rule 02 (Jantung Abnormal)}

Rule 2.1 :

IF G02 THEN K07

CFuser $=0,6$

CFrule $=1$

Rule 2.2 :

IF G10 THEN K07

CFuser $=-0,8$

CFrule $=-1,0$

Rule 2.3 :

IF G03 THEN K07

CFuser $=0,8$

CFrule $=1$

Proses perhitungan manual untuk rule 2.1 :

$$
\begin{aligned}
\mathrm{CF} \text { Gejala } 02 & =\mathrm{CF}(\text { User }) * \mathrm{CF}(\text { Pakar }) \\
& =0,6 * 1 \\
& =0,6
\end{aligned}
$$

$\mathrm{CF}_{\text {combine }}$ 2(CFold $1, \mathrm{CFgejala03)}$

$$
\begin{aligned}
& =\mathrm{CF} \text { old } 1+\mathrm{CFgejala03} *(1-\mathrm{CF} \text { old } 1) \\
& =0,92+0,8 *(1-0,92) \\
& =0,92+0,064
\end{aligned}
$$

$\mathrm{CF}_{\text {old } 2}=0,984$

Untuk mendapatkan nilai dalam bentuk persentase,

maka menggunakan rumus CF Persentase sebagai berikut :

CF Persentase $=\mathrm{CF}$ old $2 \times 100$

$=0,984 \times 100$

$=98,4 \%$

\section{Menghitung Tingkat Akurasi}

Setelah melakukan analisa data perlu untuk mencari tingkat akurasi untuk mengetahui apakah hasil analisa yang telah dilakukan memiliki tingkat akurasi yang tinggi atau rendah. Metode yang digunakan untuk menghitung nilai. akurasi dalam penelitian ini metode success rate dan kappa statistic.

\section{Success Rate}

\section{Success rate $(\mathrm{Sr})$}

merupakan ukuran pengukuran kinerja yang biasanya digunakan pada teknik klasifikasi. Seberapa sukses model yang terbentuk mampu mengklasifikasi sejumlah data berdasarkan aturan yang dihasilkan dari model yang terbentuk. Ukuran kesuksesan dilihat jika kelas suatu data dapat diprediksi dengan benar, sebaliknya jika kelas suatu data tidak dapat
Proses perhitungan manual untuk rule 2.2 :

CF Gejala 10

$$
\begin{aligned}
& =\mathrm{CF}(\text { User }) * \mathrm{CF}(\text { Pakar }) \\
& =-0,8 *-1,0 \\
& =0,8
\end{aligned}
$$

Proses perhitungan manual untuk rule 2.3 :

CF Gejala 03

$$
\begin{aligned}
& =\mathrm{CF}(\text { User }) * \mathrm{CF}(\text { Pakar }) \\
& =0,8 * 1 \\
& =0,8
\end{aligned}
$$

Dikarenakan terdapat lebih dari satu gejala, maka untuk menentukan $\mathrm{CF}$ jantung abnormal selanjutnya digunakan

persamaan (2) :

$\mathrm{CF}_{\text {combine }}$ (CFgejala02, CFgejala10)

$$
\begin{aligned}
& =\mathrm{CF} \text { gejala02+CFgejala10 } *(1-\mathrm{CF} \text { gejala02 }) \\
& =0,6+0,8 *(1-0,6) \\
& =0,6+0,32 \\
\mathrm{CF} \text { old } 1 & =0,92
\end{aligned}
$$

diprediksi dengan benar, maka dikatakan gagal/ Error.Untuk mengukur nilai SR digunakan pendekatan confusion matrix sebagai berikut:

\begin{tabular}{|c|c|c|c|}
\hline \multicolumn{2}{|c|}{} & \multicolumn{2}{c|}{ Predicated Class } \\
\cline { 3 - 4 } \multicolumn{2}{|c|}{} & Normal & Abnormal \\
\hline \multirow{2}{*}{$\begin{array}{c}\text { Actual } \\
\text { Class }\end{array}$} & Normal & $1(\mathrm{TP})$ & $9(\mathrm{FN})$ \\
\cline { 2 - 4 } & Abnormal & $0(\mathrm{FP})$ & $10(\mathrm{TN})$ \\
\hline
\end{tabular}

True Positive rate $=\mathrm{TP} /(\mathrm{TP}+\mathrm{FN})=0,1$

False Positive Rate $=$ FP $/(\mathrm{FP}+\mathrm{TN})=0$

Success rate $=(\mathrm{TP}+\mathrm{TN}) /(\mathrm{TP}+\mathrm{TN}+\mathrm{FP}+\mathrm{FN})=0,55$

Error rate $=1$ - Success Rate. $=0,45$

\section{Kappa Statistik}

Dengan demikian didapat nilai Kappa $=0,61$, maka hasil klasifikasi terbilang cukup akurat

\section{KESIMPULAN}

\subsection{Kesimpulan}

a. Penerapan Metode Certainty Factor ini memudahkan pengguna dalam memberikan jawaban terkait dengan besarnya kepercayaan terhadap gejala yang di alami dan menghasilkan hasil yang cukup akurat dalam menentukan diagnosa kelainan jantung Normal atau jantung Abnormal pada pasien tersebut.

b. Sistem pakar identifikasi kelainan jantung normal dan abnormal berdasarkan data elektrokardiogram ini dirancang dengan berbasis web agar dapat diakses secara luas dan memudahkan para medis untuk dapat mendiagnosa kelainan jantung normal dan abnormal dalam waktu yang lebih cepat. 


\subsection{Saran}

Dalam penelitian ini, saran yang dapat diberikan agar nantinya penelitian ini dapat diimplementasikan dan di penelitian selanjutnya diharapkan dapat dikembangkan lagi dengan metode dan penerapan yang lain.

\section{REFERENSI}

[1] Awaludin, Nur., (2010) Principles, Techniques, Applications, and Management, Geogrphical Information System With ArcGIS 9.X, Andi, Jogjakarta, 2010.

[2] Arifin, Mohammad. dkk. (2017). Penerapan Metode Certainty Factor Untuk Sistem Pakar Diagnosis Hama Dan Penyakit Pada Tanaman Tembakau.Berkala Sainstek V(1): 21-28

[3] Maulana, dkk. (2018). Rancang Bangun Instrumentasi Elektrokardiograf (EKG) dan Klasifikasi Kenormalan Jantung Pada Pola Sinyal EKG Menggunakan Learning Vector Quantization (LVQ). Publiser : JITCE (Journal of Information Technology and Computer Engineering), Vol.2 ( No.1), 20-26.

[4] Permana, Dian. dkk. (2015). Desain Dan Imlementasi Perancangan Elektrokardiograf (EKG) Berbasis Bluetooth. ALHAZEN Journal of Physics, Volume 2, Nomor 1.

[5] Budiyanto, Eko., (2007), Avenue Untuk Pengembangan Sistem Informasi Geografis, Andi, Jogjakarta, 2007.

[6] Awaludin, Nur., (2010) Principles, Techniques, Applications, and Management, Geogrphical Information System With ArcGIS 9.X, Andi, Jogjakarta, 2010.

[7] Budiyanto, Eko., (2007), Avenue Untuk Pengembangan Sistem Informasi Geografis, Andi, Jogjakarta, 2007.

[8] Budiyanto, Eko., (2009), Sistem Informasi dengan ArcView GIS, Andi, Jogjakarta, 2009.

[9] Dwi Arisa, Yoanita, (2009), Aplikasi GIS untuk Mencari Lokasi Cabang Warung Bu Kris Baru, Buku Tugas Akhir, Jurusan Teknologi Informasi PENS-ITS, Surabaya, 2009.

[10] GIS Konsorsium Aceh Nias, (2007), "Modul Pelatihan ArcGIS Tingkat Dasar", Banda Aceh, 2007.

[11] Keele, (1997). An Introduction to GIS using ArcView : Tutorial, Issue 1, Spring 1997 based on Arcview release 3 , http://www.keele.ac.uk/depts/cc/helpdesk/arcview/av_pr fc. htm

[12] Nuarsa, Wayan., (2005), Menganalisa Data Spasial dengan ArcView GIS 3.3, Penerbit Informatika, Bandung, 2005.

[13] Prahasta, Eddy.,(2001), Konsep-konsep Dasar Sistem Informasi Geografis, Informatika, Bandung, 2001.

[14] Prahasta, Eddy.,(2004), Sistem Informasi Geografis Tods \& Plugin, Informatika, Bandung, 2004.

[15] GIS Konsorsium Aceh Nias, (2007), "Modul Pelatihan ArcGIS Tingkat Dasar", Banda Aceh, 2007.

[16] Keele, (1997). An Introduction to GIS using ArcView : Tutorial, Issue 1, Spring 1997 based on Arcview release 3 , http://www.keele.ac.uk/depts/cc/helpdesk/arcview/av_pr fc. htm

[17] Nuarsa, Wayan., (2005), Menganalisa Data Spasial dengan ArcView GIS 3.3, Penerbit Informatika, Bandung, 2005.

[18] Prahasta, Eddy.,(2001), Konsep-konsep Dasar Sistem Informasi Geografis, Informatika, Bandung, 2001.

[19] Prahasta, Eddy.,(2004), Sistem Informasi Geografis Tods \& Plugin, Informatika, Bandung, 2004.

[20] Prahasta, Eddy., (2009), Tutorial ArcVIew, Sistem Informasi Geografis, Informatika, Bandung, 2009. 
